6. That a committee be appointed to act in conjunction with the President in compiling her annual report.

7. That all women pharmacists be recommended to join the American Pharmaceutical Association and attend its annual conventions.

8. That Standing Committees hold office until their successors are elected.

9. That the women's associations in different localities hold one joint meeting annually with the A. Ph. A. Local Branch.

10. That we take an active interest in the project for a permanent building for the American Pharmaceutical Association.

11. That when such a building is realized that the Women's Section have a Bureau of Information in the same.

12. That there be created an endowment for the Women's Section.

13. That we work to interest young women to take up the study of pharmacy and endeavor to find opportunities for young women studying pharmacy to procure practical experience.

14. That a Press Committee be appointed to report the activities of the Section to the Pharmaceutical Press.

Adelaide M. Godding, President.

A paper contributed by Miss Mary L. Creighton, Scio, Ohio, was read by Mrs. C. D. Sullivan, of Nashville, as the author was unable to attend the convention.

\title{
WOMEN'S WORK IN THE A. PH. A.
}

MARY L. CREIGHTON, PH. C., SCIO, OHIO.

The different periods which mark the world's progress have been given various names in history. The present, pharmaceutically speaking, seems to be the age of organization and of opportunities for women.

The Sixtieth Annual Convention of the A. Ph. A. is memorable in the pharmacettical calendar because of the placing of the Women's Section on the Official Roster, where it is to be thoroughly representative of women in pharmacy, whether the individual connection therewith be active or otherwise. Its officers have heard the challenge,--

"Are you in earnest? Seize this very minute:
What you can do, or think you can, begin it ;,
Boldness has genius, power and magic in it,"

and have gone enthusiastically to work to prove the right of this new Section to its place of honor as the "keystone" of the arch which has been substantially builded in the past, and which needed this final touch to give it strength and artistic completeness.

Since the active promoters of the Association's interests have disarmed prejudice, and paved the way for the more rapid progress which this federation promises for the future of pharmacy in America, it is due them that we show our appreciation of this recognition; and it will doubtless be very gratifying to the large 
number of women who have attended the annual meetings regularly, to find something in the present program strikingly different from the time-honored entertainment features provided for the ladies, who were not supposed to be interested in the discussion of matters of importance to the profession which were scheduled for consideration.

Athough the A. Ph. A. always extended them a cordial welcome to its sessions, the women members now feel a deeper sense of responsibility not only as regards the Annual Program, but extending to all the various avenues of usefulness open to those who are ready and willing to perform the tasks which may fall to them.

That women have a place in pharmacy and an important part to play in its activities has long been successfully demonstrated, and it remains for individuals to mark out, each for herself, what line of work she will choose for her share in the upbuilding of professional pharmacy in the future.

Appreciative notices are frequently given in the drug publications of women pharmacists who own and manage successful stores, as well as of the still greater number who are employed as prescriptionists. There are now comparatively few lists of graduates from Colleges of Pharmacy which do not contain the names of one or more young women, and it not infrequently happens that they secure a fair share of the prizes in competitive work.

Women are especially interested in the question of "Shorter Hours and Sunday Rest" for pharmacists generally. Real success does not mean the mere accumulation of wealth, too often at the sacrifice of all that is best and noblest in the individual, but achievement that shall benefit mankind.

Only within recent years have pharmacists, as a class, awakened to the necessity of organized and systematic effort for the betterment of their profession, and because of the fact that only a very small proportion of them have taken an active interest in matters which vitally concern their business, it has of necessity suffered a corresponding loss.

Many members of the craft apparently do not realize the claim which the associated life of pharmacy has upon their support, or are too selfish to acknowledge it; and there may still be found those who are content to leave to others the task of defending their business interests from the passage of unjust and oppressive legislation, and frequently, also, are too parsimonious to give even financial support to such efforts.

"Instead of whistling to the steeds of time"

To make them jog on merrily with life's burden,

Like a dead weight they hang upon the wheels."

One of the plain duties of the Women's Section is to assist in ridding pharmacy of this narrowness, and hasten the day when the common interest of all shall be the care of each.

While, thus far, the work has not been easy of accomplishment, the American Pharmaceutical Association is fortunate in having those in its ranks who have kept bravely on when desired results were not yet in sight.

Here, as elsewhere, the "woman's cause is man's," and with the co-operative work of both, a better day is dawning for those who realize that the wiser plan is to work toward the symmetrical development of all their God-given powers, 
thus becoming not only better pharmacists and better citizens, but having a broader view of life and its possibilities.

While we may not be able to accomplish such a wonderful transformation in the lives of those about us as did the fabled Wise Man with his unfailing "Secret of Serenity," which enabled him to meet the discouraging and unpleasant circumstances of each day with smiles and perennial cheerfulness, the habit of living on the "sunny side" is not impossible of acquirement, and means much even from the sordid level of dollars and cents.

The pharmacist, of necessity, comes in daily contact with people who are in distress because of the illness or injury of some loved one, in whose behalf his professional skill is sought, and if he can help ever so little to dispel those clouds, just so much is added to the sum total of human happiness, since

"The inner side of every cloud is bright and shining,

And if we turn our clouds about, and always wear them inside out,

They'll show the lining."

There are many organizations of a more or less local character maintained by women who are connected with pharmacy, and such bodies would be greatly strengthened by affiliating with the new Section of the $\mathrm{A}$. $\mathrm{Ph}$. A., thus securing the advantages of concentrated effort by meeting on the higher level of nationwide interests and activities, the object of which is to advance the common weal.

The Women's Section will be glad to welcome representatives from these organizations at its annual meetings, where ways and means may be found for unifying and reducing to usable form the different schemes for pharmaceutical uplift which these various groups of workers will naturally have to suggest.

The State Association meetings offer opportunities for explaining the scope and work of the A. Ph. A., and particularly of the Women's Section, to those women who annually attend these gatherings, but have, perhaps, taken no special interest in the work of the national body because its aims have not been well understood.

While the State Pharmaceutical Societies are very generally represented in the House of Delegates, it seems eminently desirable that a larger percentage of their membership should be enrolled in the $\mathrm{A}$. $\mathrm{Ph}$. A.

The branch idea is no longer in the experimental stage, but has made for itself such an important place in the list of pharmaceutical activities that it now remains to increase the number of these local organizations, in our large cities, as rapidly as possible; and women members can do much to secure a substantial growth in membership. The success which has attended the local branches already formed proves conclusively their value as a means of creating greater professional interest, and in bringing together and harmonizing the varied activities of the drug trade.

Enthusiasm is contagious and, "as one lamp lights another nor grows less," so does the enthusiastic member of any professional organization arouse interest on the part of others who had previously thought the subject of no special importance.

The plan for the establishment of permanent Official Headquarters for the American Pharmaceutical Association is one which must appeal to the entire 
membership, and which offers a field for loyal and united efforts toward its early realization on the part of all who possess the true professional spirit and have the interests of the Association at heart.

The Women's Section will doubtless rise to its opportunity, and show that "for such a time as this it has come into the kingdom." The project marks the beginning of a new achievement of vast import at present, and one which is bound to exert a powerful influence for good on the future work of the Association. A matter of prime importance in this connection is the necessity for largely increasing our membership, and this is a work in which the non-professional member may engage with as much success as those who are employed in the active duties of the store.

It is the united charge that wins the battle, each soldier in the line fighting as if victory depended upon his efforts alone, and if the members of the $\mathrm{A}$. $\mathrm{Ph}$. A. will each report for duty in the membership campaign of the next twelve months, the victory is assured.

One source from which, it seems to the writer, the Women's Section should be recruited is that for which we are indebted to such pioneers as Florence Nightingale and Clara Barton, the "Red Cross" and its branches.

The graduate nurse must possess a more or less thorough knowledge of medicines and their therapeutic effects, and be alive to the requirements of her profession. Her mission is

"To soothe and to solace,

To help and to heal

The sick world that leans on her,"

and her logical place is next to the physician who prescribes and the pharmacist who dispenses the remedies which she administers.

The non-professional member can also assist in law enforcement as to the proper inspection of food materials, especially if she herself has been appointed to that duty; one which experience has shown women to be fully competent to discharge.

On the principle that whatever benefits the community at large will benefit the pharmacist, there is in the work of civic improvement an opportunity for activity where women may follow the straight path of duty and yet be able to see the curve of beauty. So much has already been accomplished in this direction that it is plainly evident to the casual visitor in a city where the women have taken a hand in public affairs and have been instrumental in the establishment of a "clean-up day."

Whatever tends to diminish human suffering and to make this beautiful world more attractive because she has lived in it, that something is woman's work. And while the new Section is a departure from the beaten path, its members aim to make it so indispensable in the rounding out of the last half of the $\mathrm{A}$. Ph. A. Century that its usefulness as well as its justness can never be questioned.

On motion a vote of thanks was given Miss Creighton for her excellent paper.

Delegates to the House of Delegates were appointed by the chair as follows: Miss Bagley, Mrs. Beringer and Miss Farrell.

There being no further business, the meeting was adjourned to Wednesday evening at 8 o'clock. 


\section{Second Session.}

The second session was called to order by the President on Wednesday, August 20, at 8 o'clock p. m., in the assembly room of the Hotel Hermitage.

Minutes of the former session were read and approved.

The attention of the chair was called to the fact that Miss Farrell, being already a member of the House of Delegates, was not eligible to represent the Women's Section. Mrs. Whelpley was therefore appointed instead of Miss Farrell.

Papers were presented as follows:

\section{THE EARNING CAPACITY OF THE WOMAN PHARMACIST.}

\section{CLARISSA M. ROEHR, UNIVERSITY HOSPITAL, SAN FRANCISCO.}

To some this subject may not seem of sufficient importance to warrant its consideration. Within the last few years much attention has been given to conditions under which women work. For the most part these investigations have concerned women in industrial work. However, we cannot deny that the work of women for wages, whether in the industrial, commercial or professional fields, presents many problems. In literature we find page after page written on this timely subject.

In comparing one line of work with another there are many conditions which affect the right to a large or small wage, such as the agreeableness or disagreeableness of the employments, the easiness and cheapness or the difficulty and expense of learning them, the constancy or inconstancy of employment in them, the small or great trust which must be reposed in those who exercise them and the probability or improbability of success in them. Based upon these conditions the work of the pharmacist demands fairly high remuneration.

A short time ago the following statement appeared in one of the leading pharmaceutical journals: "In all lines of work in which women have entered they have caused a lowering of wages. Will the same occur in pharmacy?"

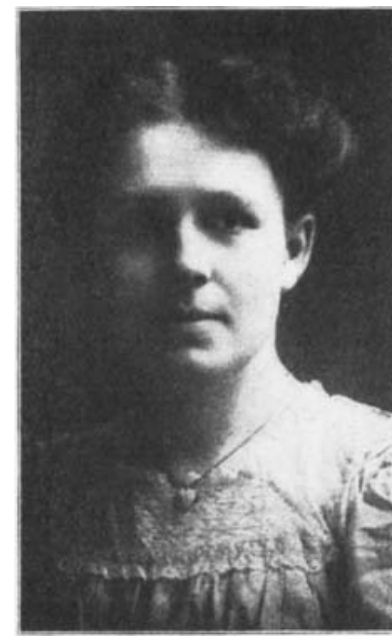

Miss Clarissa M. Roehr,

Third Vice-President Women's Section.

It is true that in many lines of industrial work women are employed at a comparatively low wage. Often they are suddenly forced into the working field, untrained and unskilled, and because of this they are compelled to accept less remuneration. Then again women enter work for a short period with no serious thought of future success nor with a desire to acquire any special training, but merely wishing to earn a little spending money. Often the work is of such a nature as to demand no training. These are the conditions which cause the lowering of wages in the industrial and commercial fields. In comparison, from the time a young man commences his education his future success is constantly held 